\title{
The Role OfThe Physician In Modern Military Operations: 12 Months Experience In Southern Iraq
}

\author{
C Grainge, $M$ Heber
}

\begin{abstract}
Objectives

To examine the profile of medical morbidity and the role of the physician in modern conflict.
\end{abstract}

\begin{abstract}
Methods
Retrospective survey of admission records at a British Military Field Hospital on operational duty in Southern Iraq.

\section{Results}

$62.5 \%$ of 4870 admissions to the Field Hospital in Shaibah during the first 12 months of military operations in Iraq were under the care of physicians. Of these $1531(31.4 \%)$ were due to diarrhoee and vomiting (D\&V) and 764 $(15.7 \%)$ due to heat illness. The incidence of heat illness rose with ambient temperature, but soldiers were more likely to be admitted with heat illness shortly after arrival in theatre than when fully acclimatised. There was also a steady flow of admissions with a broad spectrum of medical pathology requiring the clinical skills of a general physician.
\end{abstract}

\section{Conclusions}

A general physician is a necessary part of the clinical team in modern conflict. The incidence of $D \& V$ and of heat illness on military operations remains high. Planners for any operation in tropical climates should take this into consideration and put preventative measures into place early.

Surg Lt Cdr C Grainge MRCP DMCC RN Senior House Officer MDHU (Derriford), Derriford Road,

Plymouth,

PL6 8DH

Email: chrsgrain@doctors.org.uk

Col $M$ Heber MD

FRCP TD L/RAMC(V)

Consultant Cardiologist and Physician

Princess Royal Hospital, Grainger Drive,

Apley Castle,

Telford,

TF1 6TF

\section{Introduction}

Students of military history will be aware that during most military operations many more casualties are caused by disease than from injuries inflicted on the battlefield. During the Peninsular Campaign 24,930 men died from disease whilst 8,889 from battle injury. In the Crimea 17,225 died from disease and only 4102 from battle injury (1). Despite the great advance in medical science in the last 150 years, including the development of antibiotics, during a 6 month military exercise in Oman in $2001,74 \%$ of patients admitted required the attention of a physician (2). Yet still the emphasis of medical mobilisation for military operations is on surgical teams to deal with battlefield trauma (3), the roles of the physician and preventative medicine are too often forgotten.

On 24th March 2003, during the second Gulf War Conflict, a Field Hospital was established at Shaibah Air Base near Basra, Southern Iraq. Here we survey the admissions under the care of the physicians during the subsequent 12 months to examine the role of the physician during such operations and make recommendations for the possible reduction in medical morbidity in the future.

\section{Methods}

An electronic record and a written admission book were maintained of all admissions to the Field Hospital, detailing diagnosis, dates of admission and discharge and disposal on discharge. Using both sources, and cross checking between them to ensure accuracy, we constructed a data base identifying the numbers of surgical and medical admissions, the diagnosis if medical, length of stay and disposal. 'Disposal' was classified as return to duty, aero-medical evacuation back to UK, transfer to local civilian care or death.

The daily maximum air temperature at Basra airport was recorded by the Royal Air Force from 1st May 2003. Prior to this we were unable to find a record of daily temperatures, but have substituted historical monthly mean temperatures supplied by the meteorological office. Total troop numbers were obtained from military records, and recorded as mid monthly totals.

The Intensive Care Unit admission records were examined to identify the number of patients admitted and the percentage of these that were primarily for medical problems.

Patients admitted with psychiatric or stress related illness have been included in the medical numbers. Although a consultant psychiatrist was deployed initially, during the latter parts of the year these patients were admitted nominally under the care of the physician, although their management was by a Nurse led mental health care team.

\section{Results}

4870 patients were admitted during the 12 months studied, of which $4369(89.7 \%)$ were UK nationals, $345(7.1 \%)$ were Iraqi, and $156(3.2 \%)$ foreign nationals. Over the 


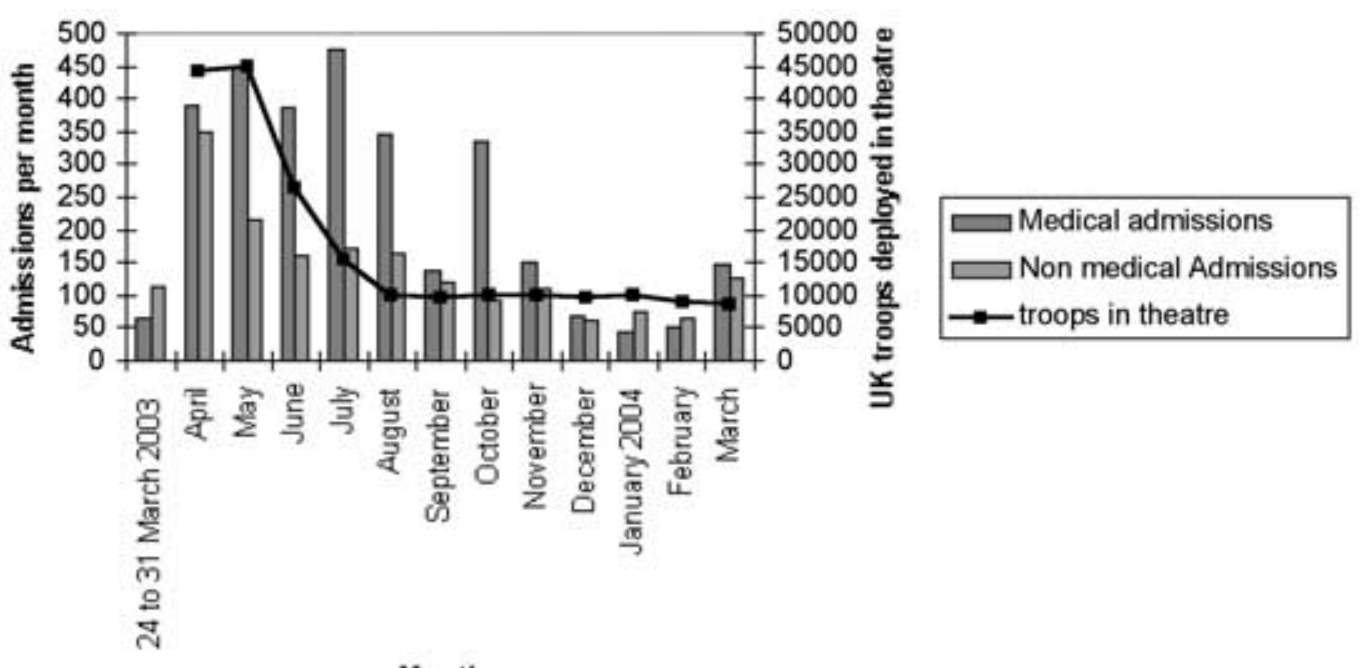

Month

Fig. 1 Medical and non medical admissions to British Military Hospital, Shaibah per month from March 2003, correlated with total number of UK troops in theatre.

course of the year $3044(62.5 \%)$ were medical, if Iraqi patients (who were usually treated by local care when not involved in trauma) were excluded the proportion of medical patients rose to $67.2 \%$. Figure 1 shows the total number of troops in theatre and the total admissions in medical and nonmedical categories per month. The proportion of admissions that fell into the medical category varied over the course of the year. During the first 6 weeks, the warfighting phase (up to the end of April), there were almost equal numbers of medical (456) and non medical (463) admissions. When ambient temperatures rose and roulement of troops occurred, medical admissions far exceeded surgical (475 compared to 170 in July) until the temperature dropped and roulement of troops was over. The total number of admissions then dropped, returning to almost equal numbers of medical (67) and non-medical (61) patients by December. Throughout the year a much higher percentage of UK forces medical patients $(83.8 \%)$ than surgical patients $(43.5 \%)$ were returned to duty, although it is noticeable that during the early warfighting stage (to the end of March) $46.8 \%$ of medical admissions were evacuated back to the UK. This is understandable, due to the uncertainty at that time as to how many battle casualties might occur, and therefore the perceived need to empty beds as fast as possible.

Figure 2 illustrates the total number of patients admitted with diarrhoea and or vomiting $(\mathrm{D} \& \mathrm{~V})$, heat illness, and other medical conditions per month and the relationship between the incidence of disease, ambient temperature and troop roulement.

Between May and August there were 752 admissions with heat related illness. The greatest number of admissions was during July (307), during the roulement period, although August was a hotter month. The number of admissions with heat related illness in September was only 7, although the temperatures were hotter $\left(46^{\circ} \mathrm{C}\right)$ than June $\left(45^{\circ} \mathrm{C}\right)$ when there were 214 admissions with heat illness. In October, with temperatures still over $40^{\circ} \mathrm{C}$, there was only a single admission with heat illness.

The numbers of admissions with $\mathrm{D} \& \mathrm{~V}$ were higher during the earlier months of the operation, although a second peak occurred after the second roulement. From December onwards the numbers admitted with this condition were very low.

The disease profile illustrated in Table 1 is very different from the average acute medical take in a District General Hospital in the UK, the highest numbers being for infectious disease and heat illness, followed by those with psychiatric problems. As shown in Table $1,608(20.0 \%)$ patients were admitted with medical diagnoses other than $\mathrm{D} \& \mathrm{~V}$, heat illness or psychiatric disorder. An interesting additional point is that 21 patients were admitted with severe hyponatraemia, caused by excessive water drinking without replacement of electrolytes, and 1 of these required intensive care.

Examination of the ITU admission register showed that out of a total of 199 admissions, $52(26.1 \%)$ were medical. Twenty of these were due to heat injury and 2 due to $\mathrm{D} \& \mathrm{~V}$. Ten $(10 \%)$ of the 100 patients admitted with respiratory disease required intensive care as did $13(15.2 \%)$ of the 85 admitted with a cardiac diagnosis. As the operation became more mature the spectrum of illness changed. Not only was the incidence of $\mathrm{D} \& \mathrm{~V}$ and psychiatric illness reduced, but other conditions such as leishmaniasis, which takes several months after infection to develop, began to appear.

\section{Discussion}

Two major discussion points arise from this survey of medical admissions during the first year of deployment in Southern Iraq. The 


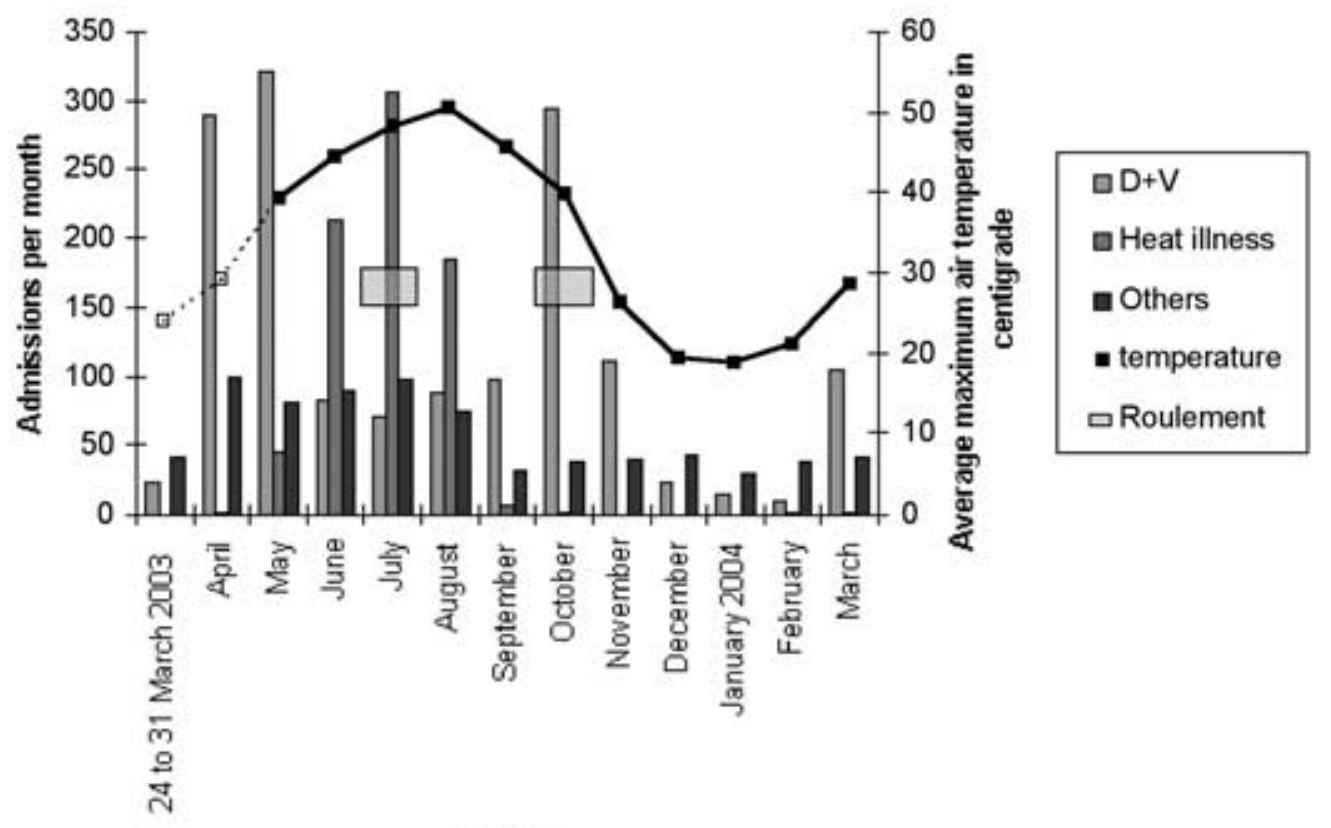

\section{Month}

Fig. 2 Medical admissions to British Military Hospital, Shaibah per month from March 2003 grouped by diagnostic categories, correlated with average monthly temperature and major roulement periods. Temperature from May 2003 recorded, prior to this historical data substituted.

first relates to the requirement and role of the physician in modern military operations, the second to the nature of disease presenting and consequently to consideration of possible preventative measures to limit medical morbidity in future operational deployments.

This survey shows that, as in previous conflicts, more patients are admitted to hospital with medical conditions than as a result of battle injury. Throughout the year there was a steady stream of medical patients with a wide spectrum of illness, requiring the professional input of an experienced physician.

The challenge of preventable disease does not seem to have been fully met. Clearly the 2 major causes of morbidity were $\mathrm{D} \& \mathrm{~V}$ and heat illness. Could these have been avoided or ameliorated?

It is well known that $\mathrm{D} \& \mathrm{~V}$ will occur when people live in close proximity with poor hygiene facilities. Is there anything that can

Table 1. Medical patients admitted to British Military Hospital, Shaibah from March 24th 2003 to 31st March 2004. Showing number in major diagnostic categories and divided by speciality, numbers and percentage admitted to the intensive care unit (ITU), number returned to unit for active duty (RTU) and average hospital stay.

\begin{tabular}{|l|c|c|c|c|}
\hline & $\begin{array}{c}\text { total } \\
\text { cases }\end{array}$ & $\begin{array}{c}\text { ITU } \\
\text { admissions (\%) }\end{array}$ & $\begin{array}{c}\text { number } \\
\text { RTU (\%) }\end{array}$ & $\begin{array}{c}\text { average } \\
\text { stay (days) }\end{array}$ \\
\hline D+V & 1531 & $2(0.1)$ & $1475(96.3)$ & 2.5 \\
\hline Heat illness & 764 & $20(2.6)$ & $606(79.3)$ & 2.9 \\
\hline Psyche & 141 & $0(0)$ & $63(44.7)$ & 2.4 \\
\hline Other & 608 & $30(4.9)$ & $389(64.0)$ & 2.9 \\
\hline
\end{tabular}

Diseases by speciality

\begin{tabular}{|l|c|c|}
\hline Infectious disease & 219 & $2(0.9)$ \\
\hline Respiratory & 100 & $10(10)$ \\
\hline Neurology & 89 & $3(3.4)$ \\
\hline Cardiology & 85 & $13(15.2)$ \\
\hline Dermatology & 54 & $0(0)$ \\
\hline Endocrinology & 29 & $1(3.4)$ \\
\hline Gastroenterology & 17 & $0(0)$ \\
\hline Rheumatology & 9 & $0(0)$ \\
\hline Haematology & 5 & $0(0)$ \\
\hline Renal & 1 & $1(100)$ \\
\hline
\end{tabular}


be done to prevent a similar casualty rate on future operations? The authors are aware from personal communication that the fly population in the hospital area during the earlier months of the operation was huge, this was dramatically reduced when drainage arrangements were improved and the deep trench latrines were replaced by Portaloos. Whilst not audited by this survey, it seems likely that similar conditions prevailed elsewhere in the operational area and that improvements in hygiene were operative in reducing the incidence of gastrointestinal disease. Hygiene arrangements are not always at the front of the minds of the senior military planners, but perhaps they should be. As in previous conflicts, our results show that more soldiers were lost from operational duties as a result of disease than battle injury. If this could be prevented, force maintenance would be enhanced, the efficiency of the fighting army improved, and our troops would be spared much needless suffering. An important lesson that should be learned, if the failures of the past are not to be continuously repeated, must be to prevent avoidable disease.

Heat illness will inevitably occur in temperatures that often reached over $50^{\circ} \mathrm{C}$. Importantly, our results show that the incidence was higher when the temperature first rose and when fresh troops, who were not used to these temperatures, first arrived in theatre. This knowledge should be acted upon when decisions regarding the time of both initial deployment and roulement to tropical areas are made. If it is essential to deploy into a tropical area at the height of summer, time must be given for acclimatisation. Planners, military or other, must be aware that performance will be impaired and that they will almost certainly suffer a reduction in the strength of their work force due to heat related illness. If at all possible initial deployment and staff changeover should take place at cooler times of the year to allow natural and gradual acclimatisation.
This survey demonstrates the high incidence of medical problems that will occur on deployment to an adverse environment, even in a young and fit population. If prevention can effectively reduce the incidence of $\mathrm{D} \& \mathrm{~V}$ and heat illness, the numbers of such admissions will diminish. However, until there is concrete evidence that this has been achieved, military medical planners and others planning medical support in similar circumstances should expect a high proportion of medical illness and plan appropriately. The figure of $67 \%$ medical admissions (of coalition deployed troops) demonstrated in this survey should be the estimate used for medical planning in future operations. Although the treatment of surgical patients tends to be more manpower intensive than that required for medical patients, all medical patients require assessment and treatment, some are very sick indeed and require time consuming intensive care. In the short term however, a much higher proportion of medical patients will return to duty after treatment than patients requiring surgery, almost all of whom will require evacuation home for recovery and recuperation, and consequently be lost from the work force. We contend that physicians are as important as surgeons and anaesthetists as part of the clinical team in modern military operations. They are required both clinically to provide the best possible treatment for the many patients admitted with medical problems, and also militarily to maximise numbers of patients returned to duty and therefore to maintain the fighting force.

\section{References}

1. Holmes R. Redcoat. chapter V, pages 249-264. London: Harper Collins; 2002.

2. Becker GW, Laundy TJ. A lesson not yet learned. $\mathcal{F}$ R Army Med Corps 2003; 149: 274-276

3. Joint Medical Doctrine: Joint Warfare Publication 403. Swindon: HMSO; 2003. 